\title{
Empreendedorismo e hotelaria como tema de pesquisa: um estudo bibliométrico das publicações do EnAnpad de 2005 a 2011
}

\section{Entrepreneurship and hospitality industry as research theme: a bibliometric study of EnAnpad 2005 to 2011}

\author{
Edson Rodrigo de Almeida (ALMEIDA, E. R. de) ${ }^{*}$ \\ Aleixina Maria Lopes Andalécio (ANDALÉCIO, A. M. L.) ${ }^{* *}$
}

RESUMO - Apresenta-se um estudo bibliométrico sobre a relação entre empreendedorismo e hotelaria. Foi desenvolvido um referencial teórico abordando esses dois temas e, para a bibliometria, foram pesquisadas as publicações apresentadas nos Encontros da Associação Nacional de Pós-Graduação e Pesquisa em Administração (EnAnpad), entre 2005 e 2011. Verificou-se a frequência de uso dos temas a partir da identificação do número de ocorrências. Levantaram-se, ainda, as principais abordagens teóricas utilizadas nos artigos que apresentaram maior frequência. $\mathrm{O}$ levantamento e a análise dos dados pesquisados permitiram concluir que os artigos publicados no EnAnpad, de 2005 a 2011, apresentam alta incidência de trabalhos que versam sobre o tema empreendedorismo e baixa incidência no tema hotelaria. Verificou-se também, dentre esses trabalhos, que um número quase insignificante trabalhou com os dois temas de forma conjunta, o que indica a existência de uma lacuna a ser preenchida pela academia.

Palavras-chave: Empreendedorismo; Hotelaria; EnAnpad; Bibliometria.

ABSTRACT - It presents a bibliometric study on the relationship between entrepreneurship and hospitality. We developed a theoretical framework addressing these two themes, and for bibliometrics, the publications surveyed were presented in the meetings of the National Association of Graduate Studies and Research in Management (ANPAD). We investigated the publications made between 2005 and 2011. From this research, we found the frequency of use of themes from the identification of the number of occurrences. The main theoretical approaches taken within the articles with high frequence were verified. It was concluded that the articles published in EnAnpad, 2005 to 2011, have a high incidence of works about the topic entrepreneurship and low incidence in the subject hotel. It was also, among these works, a number almost negligible worked with the two issues jointly, which indicates that there is a gap to be filled by the academy.

Key words: Entrepreneurship; Hospitality Industry; EnAnpad; Bibliometrics.

\footnotetext{
* Graduação em Ciências Contábeis pelo Centro Universitário de Araxá - UNIARAXÁ - Minas Gerais. Mestrado em Administração pela Faculdade Novos Horizontes - FNH (Minas Gerais). Professor do UNIARAXÁ. Endereço para correspondência: Rua Pepurure, 503. CEP: 38183-126 - Araxá - MG (Brasil). Telefone: (34) 9158-9006. E-mail: edsonrodrigo1@ hotmail.com

** Graduação em Engenheira Elétrica e em Psicologia pela Universidade Federal de Minas Gerais UFMG. Mestrado e Doutorado em Ciência da Informação pela UFMG. Professora Pesquisadora do Mestrado Acadêmico em Administração da Faculdade Novos Horizontes - FNH (Minas Gerais). Endereço para correspondência: Rua Alvarenga Peixoto, 1270. CEP: 310180-121 - Belo Horizonte - MG (Brasil). Telefone: (31) 3292-7380. E-mail: aleixina.andalecio@unihorizontes.br
} 


\section{INTRODUÇÃO}

O empreendedorismo é um tema que pode ser considerado recente e que é abordado amplamente em várias obras literárias e em artigos científicos e acadêmicos atuais no Brasil (SEIFFERT, 2005).

O desenvolvimento econômico é influenciado pelo empreendedor pelo fomento inovador provocado por ele. Porter (1992) destaca que a inovação nos processos de produção é condição crucial e fundamental para a competitividade. De acordo com Nickel, Nicolitsas e Dryden (1997), o aumento da eficiência econômica é causado pelo aumento da concorrência.

Estudo realizado por Stel, Carree e Thurik (2005) mostra que a atividade empreendedora tem efeito positivo sobre o crescimento econômico nos países ricos e efeito negativo nos países pobres, pois os países ricos usufruem de todos os lucros provenientes do crescimento, enquanto os países pobres apenas têm sua mão-de-obra popularizada. Todavia, a base de dados do referido estudo refere-se a 36 países ou observações, o que limita a validade dos resultados obtidos (STEL; CARREE; THURIK, 2005).

De acordo com Castelli (2003), a hotelaria e o turismo têm em sua história diversos momentos significativos. Com o passar dos anos, a hotelaria se diversificou e agregou serviços para que se formatasse o conceito atual. Inovação e criatividade foram implantadas e aperfeiçoadas através de desenvolvimentos tecnológicos de produtos e serviços. Esse autor ainda ressalta que tudo isso foi fundamental para iniciar um processo de padrão de qualidade e personalidade como o fator humano.

A importância dos serviços tem aumentado sua representatividade dentro da economia mundial. O turismo e a hotelaria têm destaque marcante por serem um acontecimento social e que contempla os três setores da economia, o primário, o secundário e o terciário. A hotelaria completa estruturalmente o turismo e vem crescendo enormemente nos últimos anos (CASTELLI, 2003).

Com a chegada da globalização, a competitividade passa a ser significante entre o ramo hoteleiro, surgindo assim uma maior credibilidade e confiança quanto à necessidade de um sistema de gestão a ser empregado em hotéis, possibilitando mais elementos e confiança na tomada de decisão (CASTELLI, 2003). 
Ainda, segundo Castelli (2003, p. 152), o turismo compreende as atividades realizadas pelas pessoas durante suas viagens e estadas em lugares distintos de seu entorno habitual, por um período de tempo consecutivo, inferior a um ano, por motivo de férias, negócios e outros.

O presente trabalho apresenta um estudo bibliométrico, voltado a uma abordagem sistematizada, com o objetivo a levantar dados sobre o que estava sendo estudado pela academia nos Encontros da Associação Nacional de Pós-Graduação e Pesquisa em Administração (EnAnpad), entre 2005 e 2011, associando os elementos do empreendedorismo e hotelaria.

Para embasá-lo, são apresentados a seguir conceitos relacionados aos temas empreendedorismo e hotelaria.

\section{EMPREENDEDORISMO}

O empreendedorismo desperta profundo interesse de estudos na classe acadêmica, devido a sua forte influência econômica e à capacidade de despertar novas oportunidades de negócio. Schumpeter (1984) ressalta que o empreendedor tem grande importância no cenário econômico, devido à geração de novos negócios e de empregos, dando base à expressão "destruição criativa", utilizada por ele mesmo em 1950, em referência aos termos inovação e mudança, que para o autor são os impulsionadores da criação de novos produtos.

O ato empreendedor pode ser interpretado de várias maneiras e a inovação é a mola que impulsiona a ação empreendedora. Para Schumpeter (1984), o espírito inovador do empreendedor é fator determinante para o aparecimento de novos produtos.

Estudo realizado por Reynolds et al. (2007) identificou que vários fatores afetam o nível de empreendedorismo entre os países. Em países mais desenvolvidos, a educação, a imigração e taxa de crescimento são fatores marcantes, enquanto em países menos desenvolvidos, a economia informal se destaca.

Já para Stel, Carree e Thurik (2005), a insistência em prosseguir no estudo empírico sobre o "espírito empreendedor" e sobre a economia está restrita às empresas ou localidades setorizadas. As comparações entre diferentes países são limitadas. 
Para Seiffert (2005), o estudo de Schumpeter sobre a importância do empreendedorismo para o desenvolvimento econômico e para o capitalismo foi o marco da teoria do empreendedorismo no século XX, ressaltando a importância do empreendedor no desenvolvimento econômico e na sobrevivência do capitalismo. Segundo o autor, a teoria de Schumpeter consolidou o conceito de empreendedorismo, por ele assim definido:

\begin{abstract}
Atitudes que são presentes em apenas uma pequena fração da população é que definem o tipo de empreendedor e também a função empresarial. Essa função não consiste essencialmente em inventar nada ou criar as condições para serem exploradas por uma empresa. Consiste em fazer as coisas acontecerem (SCHUMPETER, 1984, p. 132).
\end{abstract}

Para Schumpeter (1984), o empreendedor é o agente da "destruição criativa", através da constante inovação. Este fenômeno era considerado, por ele, a solução para uma sociedade capitalista burocrática, em que novos produtos deveriam ser introduzidos para manter ativa a dinâmica do mercado econômico. A função do empreendedor é social, provocando desenvolvimento econômico através de inovação (SCHUMPETER, 1984).

Seiffert (2005) ressalta que autores contemporâneos afirmam que a atividade empreendedora é determinante para o crescimento da produtividade das economias, pois transfere recursos e atividades de setores menos produtivos para outros de rendimentos mais elevados. Ainda segundo esse autor, existe uma concordância sobre a importância do empreendedor dentro do sistema econômico atual e a teoria sobre o assunto tem sido mais difundida nos últimos 30 anos, mas é considerada uma teoria ainda em formação.

\title{
3 HOTELARIA
}

Segundo relatado por Amazonas (2002), no Brasil, o desenvolvimento da hotelaria começou em 1808, após a corte real portuguesa se mudar para o país. A partir da abertura dos portos, a cidade do Rio de Janeiro passou a receber turistas de várias nações do mundo, o que impulsionou a geração dos serviços de meios de hospedagens para se adequar às necessidades dos grandes fluxos de pessoas visitantes (AMAZONAS, 2002). 
Conforme Saab e Daemom (2000), o primeiro hotel internacional no Brasil foi instalado na cidade do Rio de Janeiro somente em 1816, e batizado com o nome de Hotel Pharoux. Esses autores relatam ainda que, a partir desse momento, iniciou-se um processo de expansão de pequenos hotéis cujos serviços seguiam a tendência européia em seus serviços e na sua estrutura física.

Apenas a partir da década de 1920, a hotelaria nacional começou a ganhar identidade própria, com a inauguração do Copacabana Palace, em 1923, um hotel luxuoso e requintado que só era encontrado nos maiores centros do hemisfério europeu (DUARTE, 1997). O mesmo autor afirma que a criação, em 1966, da Empresa Brasileira de Turismo (EMBRATUR), atual Instituto Brasileiro de Turismo, foi primordial para a padronização dos hotéis no Brasil, através dos critérios de classificação através de estrelas.

Somente nos anos 90, a hotelaria nacional começou a visualizar uma nova era de crescimento e, durante o governo de Fernando Collor de Melo, o Banco Nacional de Desenvolvimento Econômico e Social (BNDES) passou a disponibilizar uma linha de crédito específica para investimentos em empreendimentos hoteleiros (ASSOCIAÇÃO BRASILEIRA DA INDÚSTRIA DE HOTEIS DO ESTADO DE SÃO PAULO, 2002).

Gorini e Mendes (2005) relatam que, com o fim do período de inflação, a partir de 1994, e a estabilização da moeda através do real, começou um novo ciclo econômico no Brasil, proporcionando à hotelaria uma expansão em sua demanda. Também comentam que o crescente aumento da renda da população e de novos investimentos de capital de empresas nacionais e estrangeiras no Brasil provocou claramente um aumento no fluxo turístico nacional e também do fluxo de estrangeiros visitantes. Contudo, esse processo culminou com a entrada de novas companhias hoteleiras e novas operadoras de serviços turísticos e a profissionalização do setor (GORINI; MENDES, 2005).

A hotelaria vem passando por vários processos de reestruturação e desenvolvimento na sua atividade, diretamente ligados à formação de mão de obra específica para a mesma. O surgimento de inúmeras instituições públicas e privadas que ofertam cursos em hotelaria e turismo em nível técnico é destacado por Faria e Quelhas (2005). O Serviço Nacional de Aprendizagem Comercial (SENAC) e o Serviço Nacional de Aprendizagem Industrial (SENAI) foram as primeiras escolas a oferecer formação técnica para a hotelaria no Brasil (ALMEIDA, 2007). 


\section{METODOLOGIA}

O procedimento adotado para realização e execução desta pesquisa foi o método denominado bibliometria. Tal método, como apresentado por Guedes e Borschiver (2005), é uma ferramenta básica de levantamento de dados estatísticos, visando quantificar os processos de comunicação escrita.

As principais leis da bibliometria, segundo Guedes e Borschiver (2005), são:

a) Lei de Bradford: ligada à dispersão da literatura periódica científica, permite estimar o grau de relevância de periódicos em dada área do conhecimento;

b) Lei de Lotka: ligada à produtividade científica de autores, considera que “alguns pesquisadores, supostamente de maior prestígio em uma determinada área do conhecimento, produzem muito e muitos pesquisadores, supostamente de menor prestígio, produzem pouco" (GUEDES; BORSCHIVER, 2005, p. 3);

c) Leis de Zipf: "permitem estimar as frequências de ocorrência das palavras de um determinado texto científico e tecnológico e a região de concentração de termos de indexação, ou palavras-chave" (GUEDES; BORSCHIVER, 2005, p. 3).

A pesquisa teve como referência a totalidade dos trabalhos publicados no Encontro da Associação Nacional de Pós-Graduação e Pesquisa em Administração (EnAnpad) no período de 2005 a 2011, num total de 6.210 artigos. A análise bibliométrica foi feita com o auxílio do software Text Filterer, da empresa Edwardsoft, Versão 3.4.

Identificaram-se, em primeiro lugar, quais artigos continham o termo 'empreendedorismo'. Em seguida, realizou-se uma nova investigação, visando filtrar todos os trabalhos que contivessem a expressão 'hotelaria'. Por fim, foi realizada uma nova filtragem, na qual foram pesquisados todos os artigos que contivessem as duas expressões juntas, 'empreendedorismo' e 'hotelaria', sendo encontrados apenas 2 artigos.

Levantou-se também o número de ocorrências dos termos e, buscando compreender como eles estavam sendo tratados nas pesquisas da área de Administração, foi verificado o conteúdo daqueles artigos com maior número de ocorrências dos termos e daqueles em que os dois apareciam de forma conjunta. 
O trabalho de pesquisa realizado não se propôs a apresentar justificativas para a utilização dos temas 'empreendedorismo' e 'hotelaria', assim como não explica sua maior relevância em determinadas áreas, visando basicamente identificar quais os rumos das pesquisas sobre esses temas e sobre a relação entre eles.

\section{ANÁLISE DOS DADOS PESQUISADOS}

Nesta seção, são apresentados os resultados encontrados na pesquisa. Primeiramente, são apresentadas as frequências de ocorrência dos termos ‘empreendedorismo' e ‘hotelaria', bem como a relação dos artigos que apresentam esses termos. Posteriormente, é explorado o uso feito desses termos nos artigos pesquisados.

\subsection{FREQÜÊNCIA DE USO DOS TERMOS EMPREENDEDORISMO E HOTELARIA}

O quadro 1 mostra, ano a ano, o total de artigos identificados em cada um dos levantamentos descritos na metodologia.

QUADRO 1 - TOTAL DE ARTIGOS POR TEMA E ANO DE PUBLICAÇÃO

\begin{tabular}{|c|c|c|c|c|c|c|c|}
\hline Período & $\begin{array}{c}\text { Total } \\
\text { de } \\
\text { artigos }\end{array}$ & $\begin{array}{c}\text { Artigos com o } \\
\text { termo } \\
\text { empreendedorismo }\end{array}$ & $\%$ & $\begin{array}{c}\text { Artigos com } \\
\text { o termo } \\
\text { hotelaria }\end{array}$ & $\%$ & $\begin{array}{c}\text { Artigos com os } \\
\text { termos } \\
\text { empreendedorismo } \\
\text { e hotelaria }\end{array}$ & $\%$ \\
\hline 2005 & 791 & 69 & 1,11 & 15 & 0,24 & 0 & 0,00 \\
\hline 2006 & 836 & 85 & 1,37 & 26 & 0,42 & 1 & 0,02 \\
\hline 2007 & 973 & 104 & 1,67 & 16 & 0,26 & 1 & 0,02 \\
\hline 2008 & 1.001 & 118 & 1,90 & 25 & 0,40 & 0 & 0,00 \\
\hline 2009 & 905 & 88 & 1,42 & 11 & 0,18 & 0 & 0,00 \\
\hline 2010 & 841 & 88 & 1,42 & 12 & 0,19 & 0 & 0,00 \\
\hline 2011 & 863 & 105 & 1,69 & 15 & 0,24 & 0 & 0,00 \\
\hline Total & 6.210 & 657 & 10,5 & 120 & 1,93 & 2 & 0,03 \\
\hline
\end{tabular}

FONTE: DADOS DA PESQUISA, 2012.

Os dados apresentados no quadro 1 revelam que, dentre todos os 6.210 artigos publicados no EnAnpad, de 2005 a 2011, 10,58\% (657 artigos) fizeram referência ao tema 'empreendedorismo', 1,93\% (120 artigos) utilizaram o termo 'hotelaria' e em apenas dois artigos esses termos apareceram conjuntamente. Analisando ano a ano, em 
2005, 2006, 2007, 2008, 2009, 2010 e 2011, respectivamente, 1,11\% (69), 1,37\% (85), 1,67\% (104), 1,90\% (118), 1,42\% (88), 1,42\% (88) e 1,69\% (105) dos trabalhos publicados no período citam a palavra 'empreendedorismo'. Já em relação à expressão 'hotelaria', analisando os mesmos anos, encontrou-se 0,24\% (15), 0,42\% (26), 0,26\% (16), 0,40\% (25), 0,18 (11), 0,19 (12) e 0,24\% (15) de trabalhos publicados com essa expressão.

Constata-se, a partir desses dados, a importância do tema 'empreendedorismo' para os estudos da academia. Em 2008, ano de maior ocorrência, o percentual de incidência desse tema entre os artigos publicados representa 17,96\% (118) do total de artigos que utilizaram o termo de 2005 a 2011. Nos demais anos, a frequência com a qual o tema empreendedorismo é usado se mantém, em média, na casa dos 13,67\% (90). O quadro 2 mostra a ocorrência da palavra 'empreendedorismo' por artigo, nos cinquenta artigos que mais citaram o termo em todo o período pesquisado..

QUADRO 2 - RELAÇÃO DOS CÓDIGOS E TÍTULOS DOS ARTIGOS ENANPAD COM O TERMO 'EMPREENDEDORISMO', 2005 A 2011.

\begin{tabular}{|c|c|c|}
\hline $\begin{array}{c}\mathrm{N}^{\circ} \text { de } \\
\text { ocorrências }\end{array}$ & Código & Título \\
\hline 105 & GCT-329 & $\begin{array}{l}\text { Empreendedorismo em diferentes tipos de organizações: análise da } \\
\text { produção científica na base de dados SciELO: } 2004-2008\end{array}$ \\
\hline 104 & GCTC -1212 & $\begin{array}{l}\text { Metodologias, recursos e práticas didático-pedagógicas no ensino } \\
\text { de empreendedorismo em cursos de graduação e pós-graduação } \\
\text { nacionais e internacionais. }\end{array}$ \\
\hline 101 & ESOC-1701 & $\begin{array}{l}\text { O Fenômeno do empreendedorismo e as teorias organizacionais: } \\
\text { identificando a interseção teórica dos domínios. }\end{array}$ \\
\hline 97 & EPQ-567 & $\begin{array}{l}\text { Ensino de empreendedorismo nos cursos de graduação em } \\
\text { administração na cidade de Fortaleza: um estudo comparativo dos } \\
\text { conteúdos e instrumentos pedagógicos. }\end{array}$ \\
\hline 93 & ESO-C787 & Constituição ontoteleológica do empreendedorismo. \\
\hline 91 & EPQ-A1551 & O empreendedorismo e o ensino universitário: um estudo de caso. \\
\hline 89 & ESO-C2015 & Estudo sobre a essência do empreendedorismo. \\
\hline 86 & EPQ-C211 & Dimensões epistemológicas da pesquisa em empreendedorismo. \\
\hline 83 & ESO1411 & Esboço para uma teoria tridimensional do empreendedorismo. \\
\hline 75 & ESO-2080 & $\begin{array}{l}\text { Empreendedorismo, Crescimento Econômico e Competitividade } \\
\text { dos BRICS: Uma Análise Empírica a partir dos Dados do GEM e } \\
\text { GCI. }\end{array}$ \\
\hline 73 & GCT-2573 & $\begin{array}{l}\text { Empreendedorismo Sustentável: Proposição de uma Tipologia e } \\
\text { Sugestões de Pesquisa. }\end{array}$ \\
\hline 72 & ESO-C1026 & $\begin{array}{l}\text { Empreendedorismo e Competência: um ensaio sobre a } \\
\text { complementaridade e a convergência dos construtos. }\end{array}$ \\
\hline 71 & ESO1460 & $\begin{array}{l}\text { Empreendedorismo, Competitividade e Crescimento Econômico: } \\
\text { algumas evidências empíricas. }\end{array}$ \\
\hline 70 & ESO-C816 & $\begin{array}{l}\text { Rupturas, permanências e ressignificações na estrutura discursiva } \\
\text { do empreendedorismo. }\end{array}$ \\
\hline
\end{tabular}




\begin{tabular}{|c|c|c|}
\hline $\begin{array}{c}\mathbf{N}^{\mathbf{0}} \text { de } \\
\text { ocorrências }\end{array}$ & Código & Título \\
\hline 69 & ESO189 & $\begin{array}{l}\text { O empreendedorismo sustentável e o processo empreendedor: em } \\
\text { busca de oportunidades de novos negócios como solução para } \\
\text { problemas sociais e ambientais. }\end{array}$ \\
\hline 68 & GCT1958 & $\begin{array}{l}\text { O empreendedorismo compreendido sob a perspectiva dos estudos } \\
\text { culturais: a contribuição teórica do circuito da cultura. }\end{array}$ \\
\hline 67 & EPQ1581 & $\begin{array}{l}\text { Aprendizagem em Empreendedorismo dos acadêmicos do curso de } \\
\text { administração de uma universidade estadual no sul do Brasil. }\end{array}$ \\
\hline 67 & ESO1561 & $\begin{array}{l}\text { Capital humano, empreendedorismo e desenvolvimento econômico: } \\
\text { evidências empíricas nos municípios do Ceará. }\end{array}$ \\
\hline 66 & ESO-C1347 & $\begin{array}{l}\text { Empreendedorismo feminino: análise da produção científica da base } \\
\text { de dados do Institute for Scientific Information (ISI), 1997-2006. }\end{array}$ \\
\hline 65 & ESO-C2571 & $\begin{array}{l}\text { Configuração empreendedora ou configurações empreendedoras? } \\
\text { Indo um pouco além de Mintzberg. }\end{array}$ \\
\hline 64 & ESO1421 & Sentido axiológico do empreendedorismo. \\
\hline 61 & EOR-1980 & O Desafio do Empreendedorismo Feminino \\
\hline 61 & ESO-C895 & $\begin{array}{l}\text { A Dinâmica das ações nas organizações do terceiro setor e sua } \\
\text { relação com o empreendedorismo social. }\end{array}$ \\
\hline 59 & ESO-C2575 & $\begin{array}{l}\text { Empreendedorismo como estratégia corporativa na perspectiva } \\
\text { institucional de análise: estudo de caso. }\end{array}$ \\
\hline 58 & EOR1586 & $\begin{array}{l}\text { A alavanca que move o mundo: o discurso da mídia de negócios } \\
\text { sobre o capitalismo empreendedor. }\end{array}$ \\
\hline 57 & ESO-C706 & $\begin{array}{l}\text { Estruturação e implantação de um programa de empreendedorismo } \\
\text { social: o caso do SESI Paraná. }\end{array}$ \\
\hline 56 & EPQ1539 & $\begin{array}{l}\text { Cultura empreendedora: } \text { o } \text { que está sendo produzido na } \\
\text { administração? }\end{array}$ \\
\hline 55 & GCT245 & $\begin{array}{l}\text { Empreendedorismo Social: um estudo da relação entre os elementos } \\
\text { constituintes do empreendedorismo e a gestão de organizações } \\
\text { sociais. }\end{array}$ \\
\hline 53 & GCT-C3196 & $\begin{array}{l}\text { Empreendedorismo e visão baseada em recursos: uma nova } \\
\text { perspectiva de análise. }\end{array}$ \\
\hline 52 & EOR-695 & $\begin{array}{l}\text { O Consenso, o Exemplo e a Inexorabilidade: Discursos } \\
\text { Hegemônicos acerca do Empreendedorismo como Mecanismo de } \\
\text { Reprodução do Capital. }\end{array}$ \\
\hline 48 & GCT-D317 & $\begin{array}{l}\text { Implementação de estratégia empreendedora internacional no setor } \\
\text { de vinhos: o caso da Vinícola Miolo. }\end{array}$ \\
\hline 47 & GCT928 & $\begin{array}{l}\text { Empreendedorismo: área em evolução? Uma revisão dos estudos e } \\
\text { artigos publicados entre } 2001 \text { e } 2008 \text {. }\end{array}$ \\
\hline 46 & EOR1179 & Mulheres empreendedoras: retrospectiva e perspectivas de estudos. \\
\hline 46 & EOR-A686 & $\begin{array}{l}\text { Linguagem, relações de poder e o mundo do trabalho: a construção } \\
\text { discursiva do conceito de empreendedorismo. }\end{array}$ \\
\hline 46 & ESO-C1841 & $\begin{array}{l}\text { Quem não arrisca não petisca? Uma análise empírica da associação } \\
\text { entre empreendedorismo e tolerância ao risco. }\end{array}$ \\
\hline 46 & ESO-C2556 & $\begin{array}{l}\text { Ensino do empreendedorismo na educação básica, voltado para o } \\
\text { desenvolvimento econômico e social sustentável: um estudo sobre a } \\
\text { metodologia "Pedagogia Empreendedora" de Fernando Dolabela. }\end{array}$ \\
\hline 43 & ESO-C1910 & $\begin{array}{l}\text { Instrumento de medida da atitude empreendedora } \\
\text { construção e validação de uma escala. }\end{array}$ \\
\hline 43 & ESO-B313 & $\begin{array}{l}\text { Estratégias e determinantes da internacionalização de pequenas e } \\
\text { médias empresas (PMEs): abordagem da teoria de redes de } \\
\text { relacionamento e empreendedorismo. }\end{array}$ \\
\hline 42 & GCT-1105 & $\begin{array}{l}\text { Empreendedorismo Social: do Contexto Político às Práticas de } \\
\text { Implementação - Um Estudo de Experiências no Brasil e sua } \\
\text { Aproximação à Realidade de Portugal }\end{array}$ \\
\hline
\end{tabular}




\begin{tabular}{|c|c|c|}
\hline $\begin{array}{c}\mathrm{N}^{\circ} \mathrm{de} \\
\text { ocorrências }\end{array}$ & Código & Título \\
\hline 41 & ESO-C2664 & $\begin{array}{l}\text { Propensão ao empreendedorismo dos alunos do ensino } \\
\text { fundamental: um estudo comparativo com alunos de } 7^{\mathrm{a}} \text { e } 8^{\mathrm{a}} \text { séries, } \\
\text { entre instituições de ensino municipais e privadas de Maceió. }\end{array}$ \\
\hline 41 & EOR2776 & $\begin{array}{l}\text { A Construção do processo de sucessão empreendedora em empresas } \\
\text { familiares. }\end{array}$ \\
\hline 41 & ESO-C1116 & $\begin{array}{l}\text { Integrando o aluno do curso de administração na questão da } \\
\text { responsabilidade social: programa integrado de capacitação } \\
\text { empreendedora. }\end{array}$ \\
\hline 41 & ESO-C1289 & $\begin{array}{l}\text { Proposições preliminares para facilitar o empreendedorismo em } \\
\text { organizações de TI. }\end{array}$ \\
\hline 40 & GCT-C1630 & $\begin{array}{l}\text { Atitude empreendedora em proprietários-gerentes de pequenas } \\
\text { empresas. Construção de um instrumento de medida IMAE. }\end{array}$ \\
\hline 40 & ESO-C1779 & $\begin{array}{l}\text { Preditores do perfil empreendedor dos discentes dos cursos de } \\
\text { Administração. }\end{array}$ \\
\hline 40 & ESO-C2043 & As conseqüências do empreendedorismo nas organizações. \\
\hline 36 & EPQ-A2763 & $\begin{array}{l}\text { As contribuições do curso de Administração de Empresas na atitude } \\
\text { empreendedora dos seus discentes: o caso da Faculdade OPET. }\end{array}$ \\
\hline 35 & ESO-C2231 & 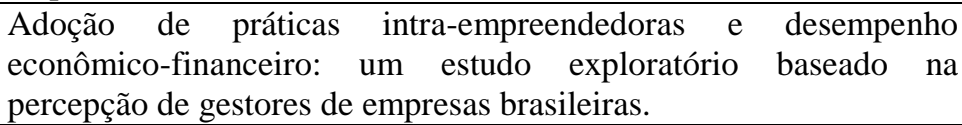 \\
\hline 34 & ESO-C1764 & Empreendedorismo no Brasil: uma atividade sem "espírito"? \\
\hline 33 & ESO-C2150 & $\begin{array}{l}\text { Intra empreendedorismo social: uma análise auto-avaliativa dos } \\
\text { funcionários de uma mantenedora religiosa. }\end{array}$ \\
\hline
\end{tabular}

FONTE: DADOS DA PESQUISA, 2012.

Percebe-se que $78 \%$ (39 artigos) dos trabalhos relacionados no quadro 2 contêm em seu título, ora a palavra 'empreendedorismo', ora uma referência direta ao tema. Também constatou-se que 24\% (12 artigos), apesar de não conterem a palavra 'empreendedorismo', possuíam palavras similares, que fazem ligação direta com o termo. Tal constatação evidencia que, nesses casos, o termo 'empreendedorismo' não aparece como uma mera citação, mas sim como tema central dos trabalhos. Dentre estes, os cinco artigos com o maior número de citações apresentam uma frequência que varia de 93 a 105 ocorrências, conforme mostram os dados apresentados no quadro 2.

A pesquisa também mostrou que, dos 6210 artigos publicados entre 2005 e 2011, apenas 120 artigos mencionam a expressão 'hotelaria', o que corresponde a $1,93 \%$ do total publicado no período. O ano de 2006 foi o que mais apareceu com publicações contendo essa expressão, com um total de 26 artigos, correspondendo ao percentual de $0,42 \%$ dos artigos publicados. $\mathrm{O}$ ano de 2008 foi o segundo em número de publicações, com 25 publicações, correspondendo a $0,40 \%$ do total. O quadro 3 apresenta a frequência da expressão hotelaria nos 10 artigos em que ela aparece mais frequentemente. 
QUADRO 3 - RELAÇÃO DOS CÓDIGOS E TÍTULOS DOS ARTIGOS ENANPAD COM O TERMO HOTELARIA, 2005 A 2011.

\begin{tabular}{|c|c|c|}
\hline $\begin{array}{c}\mathbf{N}^{\mathbf{o}} \text { de } \\
\text { ocorrências }\end{array}$ & Código & Título \\
\hline 33 & GCT-B1857 & $\begin{array}{l}\text { Inovação em serviços: estudo de casos de inovação tecnológica em } \\
\text { uma organização hoteleira. }\end{array}$ \\
\hline 28 & GPR-2717 & O Desenvolvimento de Competências no Setor Hoteleiro Capixaba \\
\hline 20 & GCT-2508 & $\begin{array}{l}\text { Serviços em Hotelaria: Estudo de Casos sobre Inovação em } \\
\text { Hospitalidade }\end{array}$ \\
\hline 20 & GPR-A2893 & $\begin{array}{l}\text { Aprendendo na prática: como os gerentes de meios de hospedagem } \\
\text { aprendem no contexto prático-social? }\end{array}$ \\
\hline 12 & GTC-1530 & $\begin{array}{l}\text { O peso dos ativos específicos na diferenciação das firmas que } \\
\text { compõem o setor hoteleiro de porto alegre: uma análise exploratória à } \\
\text { luz da economia dos custos de transação }\end{array}$ \\
\hline 11 & EOR-378 & $\begin{array}{l}\text { Aprendizagem Individual e Organizacional na Recepção de um } \\
\text { Equipamento Hoteleiro: uma Análise sobre como os Funcionários } \\
\text { desse Setor Aprendem a Desenvolver suas Atividades de Trabalho. }\end{array}$ \\
\hline 11 & GCT-B2789 & $\begin{array}{l}\text { Inovação na indústria hoteleira: complementação entre inovações } \\
\text { tecnológicas e inovações baseadas em serviços. }\end{array}$ \\
\hline 11 & FIC-B2731 & $\begin{array}{l}\text { Avaliação da estrutura da gestão de custos no setor de hospedagem } \\
\text { dos hotéis nordestinos: um estudo nos estados do Rio Grande do } \\
\text { Norte, Paraíba e Pernambuco. }\end{array}$ \\
\hline 9 & GPR-A2606 & $\begin{array}{l}\text { A avaliação de RH no setor hoteleiro: um estudo de caso nas maiores } \\
\text { redes do Brasil. }\end{array}$ \\
\hline 8 & GPR-926 & $\begin{array}{l}\text { Seriam as Âncoras de Carreira Aderente às Carreiras Inteligentes?: } \\
\text { Um Estudo Comparativo entre Alunos Formandos de um curso de } \\
\text { Administração de Empresas e de Hotelaria e Turismo }\end{array}$ \\
\hline 8 & GCT-B2945 & $\begin{array}{l}\text { Abordagem funcional da produção de serviços e lógicas de inovação: } \\
\text { análise de casos em hospitais brasileiros e franceses }\end{array}$ \\
\hline 7 & MKT-C261 & $\begin{array}{l}\text { Distribuição eletrônica na hotelaria: desenvolvimento de serviços para } \\
\text { a Internet. }\end{array}$ \\
\hline 7 & MKT-A2331-1 & $\begin{array}{l}\text { Encontros de Serviços de Hospitalidade: o gerenciamento de } \\
\text { impressões de funcionários de linha de frente e a satisfação do } \\
\text { hóspede em foco. }\end{array}$ \\
\hline 7 & ESO-A1695 & $\begin{array}{l}\text { Planejamento estratégico e operacional na pequena empresa: impactos } \\
\text { da formalização no desempenho e diferenças setoriais. }\end{array}$ \\
\hline 7 & GCT-C903 & $\begin{array}{l}\text { Atitude empreendedora no setor hoteleiro brasileiro: um estudo em } \\
\text { pequenos e grandes hotéis no Distrito Federal. }\end{array}$ \\
\hline
\end{tabular}

FONTE: DADOS DA PESQUISA, 2012.

Identifica-se que, dos trabalhos relacionados no quadro 3, apenas 20\% (3 artigo) contêm em seu título a expressão 'hotelaria' em uma referência direta ao tema. Também se verificou que 53,33\% (7 artigos) possuíam em seu título alguma expressão que indica assunto relacionado à hotelaria e 33,33\% (5 artigos) não mencionavam de nenhuma forma a expressão. Nos artigos com a citação direta à expressão 'hotelaria', a frequência de ocorrências da expressão foi de 35 vezes nos textos dos artigos.

Foram encontrados apenas dois artigos que, em conjunto, contêm as duas expressões no seu conteúdo, conforme pode ser visto no quadro 4. 
QUADRO 4 - RELAÇÃO DOS CÓDIGOS E TÍTULOS DOS ARTIGOS ENANPAD COM OS TERMOS 'EMPREENDEDORISMO' E 'HOTELARIA', 2005 A 2011

\begin{tabular}{|c|c|lc|}
\hline $\begin{array}{c}\mathbf{N}^{\mathbf{0}} \text { de } \\
\text { ocorrências }\end{array}$ & Código & \multicolumn{1}{|c|}{ Título } \\
\hline 6 & APSC2814 & $\begin{array}{l}\text { A responsabilidade social em estabelecimentos turísticos de } \\
\text { hospedagem: um estudo na Estrada Real/MG }\end{array}$ \\
\hline 6 & EPQC90 & $\begin{array}{l}\text { Perspectivas acadêmicas em São Luis: A aproximação entre o estudo } \\
\text { do turismo e a ciência da administração }\end{array}$ \\
\hline
\end{tabular}
FONTE: DADOS DA PESQUISA, 2012.

\subsection{ANÁLISE DA APLICABILIDADE DO TERMO 'EMPREENDEDORISMO' ENTRE OS ARTIGOS PESQUISADOS}

A maioria dos artigos se destaca pela frequência de uso e adoção do termo empreendedorismo como temática central. Nesse contexto, o artigo "Empreendedorismo em diferentes tipos de organizações: análise da produção científica na base de dados do Scientific Electronic Library Online (SciELO): 2004-2008” contém o maior número de ocorrências do tema, num total de 105 citações. Esse trabalho visa apresentar a publicação de trabalhos científicos com base no empreendedorismo como estratégia empresarial fazendo um estudo bibliográfico com análise de conteúdo na base de dados do Scientific Electronic Library Online (SciELO), no período de 2004 a 2008, para atingir seu objetivo.

O segundo artigo a apresentar o maior número de ocorrências sobre o tema empreendedorismo intitula-se "Metodologias, recursos e práticas didático-pedagógicas no ensino de empreendedorismo em cursos de graduação e pós-graduação nacionais e internacionais". Ao todo, a palavra empreendedorismo é citada 104 vezes. O objetivo do trabalho é o de realizar um levantamento "do estado da arte das metodologias e práticas didático-pedagógicas utilizadas no ensino de empreendedorismo nos cursos de graduação e pós-graduação nacionais e estrangeiros.” (HENRIQUE; CUNHA, 2006, p. $1)$.

Já o artigo intitulado "O Fenômeno do Empreendedorismo e as teorias organizacionais: identificando a interseção teórica dos domínios” (RODRIGUES, 2007), que cita a palavra empreendedorismo 101 vezes, apresenta como objetivo "modelar o fenômeno empreendedorismo em relação às teorias organizacionais, especialmente aquela desenvolvida por Mintzberg". 
Com 97 citações, o artigo "Ensino de empreendedorismo nos cursos de graduação em administração na cidade de Fortaleza: um estudo comparativo dos conteúdos e instrumentos pedagógicos" relaciona o tema empreendedorismo com a metodologia aplicada no ensino das disciplinas deste tema nas instituições de ensino superior da cidade de Fortaleza, considerando que "o conceito de empreendedorismo, na medida em que evolui e aumenta sua percepção por meio de pesquisas, tende a se tornar um guia relevante para a elaboração de conteúdos e práticas nas IES" (ROCHA; BACCHI, 2010, p. 10).

No artigo "Constituição ontoteleológica do empreendedorismo", o termo empreendedorismo foi citado 93 vezes. Trata-se de um estudo voltado à complexidade de se dar uma definição do termo empreendedorismo. A questão central enfatizada nesse trabalho fica evidenciada na citação abaixo:

\footnotetext{
Neste estudo, observou-se que a constituição ontoteleológica do empreendedorismo assenta-se no chamado meta empreendedorismo, que utiliza-se de uma abordagem transdisciplinar. Demonstrou-se ainda que as investigações efetuadas não obtiveram sucesso na busca pela "natureza" do empreendedorismo. Isso se deve a dois motivos: 1) a fase préparadigmática em que o ramo se encontra; 2) ênfase em estudos ônticos. (BOAVA; MACÊDO, 2007, p. 12).
}

Em outros artigos em que o empreendedorismo surge como temática central analisam-se as seguintes questões:

a) Avaliação da eficiência do ensino do Empreendedorismo no Curso de Administração;

b) O empreendedorismo como objeto de pesquisa;

c) Teoria do empreendedorismo;

d) Empreendedorismo e suas competências;

e) Empreendedorismo e competitividade nas empresas;

f) A estrutura do empreendedorismo e o processo empreendedor;

g) A cultura do empreendedorismo;

h) Empreendedorismo e a relação com o capital humano.

Os demais artigos apresentados no quadro 2 restringiram-se a citar o termo empreendedorismo do forma circunstancial. Nesse sentido, a palavra empreendedorismo 
apresenta-se como elemento subjetivo, não tendo influência marcante no objeto de estudo deste trabalho.

\subsection{ANÁLISE DA APLICABILIDADE DO TERMO HOTELARIA NOS ARTIGOS PESQUISADOS}

O artigo com o maior número de citações do termo hotelaria, com 33 ocorrências, foi o artigo intitulado "Inovação em serviços: estudo de casos de inovação tecnológica em uma organização hoteleira" (KLEMENT; YU, 2008), o qual trata do crescimento dos serviços e sua importância para a economia e importância da inovação para a competitividade.

Em segundo lugar, com 28 citações, encontra-se o artigo "O Desenvolvimento de Competências no Setor Hoteleiro Capixaba" (MELLO; PIMENTEL, 2010), cujo objetivo foi identificar as competências profissionais requeridas pelo setor turístico e analisar como os trabalhadores deste setor adquirem essas competências.

Com 20 citações, o artigo "Serviços em Hotelaria: Estudo de Casos sobre Inovação em Hospitalidade" (KLEMENT, 2010) ocupa o terceiro lugar em número de ocorrências do termo. Trata-se do relato de pesquisa que visou analisar o alcance da aplicabilidade do modelo conceitual de Gallouj e Weinstein sobre inovação em serviços, através de estudo de casos no setor de hotelaria da cidade de Vitória/ES.

O quarto artigo, também com 20 citações, é "Aprendendo na prática: como os gerentes de meios de hospedagem aprendem no contexto prático-social?”, que relata estudo sobre como é o meio de aprendizagem dos gerentes do setor hoteleiro de Recife (DIDIER; LUCENA, 2008).

$\mathrm{O}$ quinto artigo, com o título "O peso dos ativos específicos na diferenciação das firmas que compõem o setor hoteleiro de Porto Alegre: uma análise exploratória à luz da economia dos custos de transação" (MARQUESAN et al.), com 12 citações do termo hotelaria, apresenta uma comparação do valor das especificidades dos ativos de 23 hotéis das categorias 'Luxo' e 'Superior', localizados em Porto Alegre, com os preços médios das diárias cobradas por eles.

O restante dos artigos apresentados no quadro 3 abordam outras temáticas, como:

a) Planejamento estratégico; 
b) Gerenciamento de funcionários;

c) Estrutura de custos;

d) Avaliação de recursos humanos.

\subsection{ANÁLISE DA APLICABILIDADE DOS ARTIGOS CONTENDO OS TERMOS EMPREENDEDORISMO E HOTELARIA EM CONJUNTO NOS ARTIGOS PESQUISADOS}

O primeiro artigo a mencionar os termos 'empreendedorismo' e 'hotelaria' conjuntamente, com 6 citações, foi o artigo com o título "A responsabilidade social em estabelecimentos turísticos de hospedagem: um estudo na Estrada Real/MG", apresentado no EnAnpad no ano de 2006. O estudo não faz qualquer relação entre os dois temas, abordando-os em óticas distintas dentro do trabalho. $\mathrm{O}$ trecho a seguir reflete o conteúdo do artigo citado:

\footnotetext{
O presente estudo trata da Responsabilidade Social, ao analisar a prática em estabelecimentos de hospedagem da Estrada Real/MG, sob quatro aspectos: econômico/financeiro, político/ético, social e ambiental. Foi utilizada uma abordagem do tipo descritiva, e coleta de dados através de questionário em escala likert, formulado com base em indicadores de responsabilidade social (CARVALHO; ALBERTON, 2006, p. 2).
}

O segundo artigo, também com 6 citações dos termos, foi publicado no EnAnpad em 2007, com o título "Perspectivas acadêmicas em São Luis: a aproximação entre o estudo do turismo e a ciência da administração" (MIRANDA, 2007). Trata da inserção do estudo da administração nos cursos de turismo e a sua aplicabilidade, não traçando, em nenhum ponto, a relação entre o empreendedorismo e a hotelaria.

\section{CONSIDERAÇÕES FINAIS}

A estruturação científica do fenômeno empreendedorismo vem avançando significativamente nas últimas décadas. Trata-se de um campo de pesquisa relativamente recente e, cada vez mais, seu avanço representa uma consequência da necessidade atual de compreender-se a essência de sua existência. Da mesma forma, devido ao avanço do turismo como atividade econômica, a hotelaria vem se tornando um tema de interesse para a comunidade científica. 
O objetivo desse estudo foi identificar como vêm sendo tratados os termos 'empreendedorismo' e 'hotelaria' no ambiente acadêmico. Para tal, foi feita uma pesquisa bibliométrica, tendo como referência os artigos publicados no EnAnpad, no período de 2005 a 2011.

Observou-se que, na área da Administração, o termo 'empreendedorismo' aparece de forma mais recorrente que o termo 'hotelaria', o que parece coerente com o fato de que o empreendedorismo constitui um campo de estudo dessa área, enquanto a hotelaria costuma interessar mais à área do Turismo. Foram encontrados apenas dois artigos que utilizaram os dois termos juntos, mas mesmo esses não relacionavam os dois assuntos diretamente.

Tal fato pode ser considerado como um indício de que a academia não vem se preocupando em realizar estudos sobre a relação entre os dois termos, focando apenas nos interesses específicos dessas duas áreas de conhecimento, a Administração e o Turismo. Isso evidencia a existência de uma lacuna a ser preenchida por estudos voltados para essa dupla temática.

\section{REFERÊNCIAS}

ASSOCIAÇÃO BRASILEIRA DA INDÚSTRIA DE HOTEIS DO ESTADO DE SÃO PAULO. Informações sobre a hotelaria nacional. Revista Mix Hotel. São Paulo, 2002.

ALMEIDA, M. A. de. Percepção de gestores e técnicos sobre o processo de gestão de competências em organizações no Brasil. 2007. 131 f. Dissertação (Mestrado em Gestão Social e Trabalho) - Universidade de Brasília, Brasília, 2007. Disponível em: <http://repositorio.bce.unb.br/bitstream/10482/3556/1/2007_Marcelo

AraujodeAlmeida.PDF >. Acesso em: 19/12/2011.

AMAZONAS, E. A hotelaria no mundo. Portal Hoteleiro, 2002. Disponível em: $<$ http://www.revistahoteis.com.br/portal/historia/historia.htm>. Acesso em: 01/12/2011.

BOAVA, D. L. T; MACÊDO, F. M. F. Constituição ontoteleológica do empreendedorismo. In: ENCONTRO DA ASSOCIAÇÃO NACIONAL DE PÓSGRADUAÇÃO E PESQUISA EM ADMINISTRAÇÃO, 2007. Rio de Janeiro. Anais... Rio de Janeiro: ANPAD, 2007. CD ROM.

CARVALHO, A. N.; ALBERTON, A. A responsabilidade social em estabelecimentos turísticos de hospedagem: um estudo na Estrada Real/MG. In: ENCONTRO DA ASSOCIAÇÃO NACIONAL DE PÓS-GRADUAÇÃO E PESQUISA EM ADMINISTRAÇÃO, 2006. Bahia. Anais... Salvador: ANPAD, 2006. CD ROM. 
CASTELLI, G. Administração hoteleira. Caxias do Sul: Educs, 2003.

DIDIER, J. M. O. L.; LUCENA, E. A. Aprendendo na prática: como os gerentes de meios de hospedagem aprendem no contexto prático-social? In: ENCONTRO DA ASSOCIAÇÃO NACIONAL DE PÓS-GRADUAÇÃO E PESQUISA EM ADMINISTRAÇÃO, 2008. Rio de Janeiro. Anais... Rio de Janeiro: ANPAD, 2008. CD ROM.

DUARTE, V. V. Administração de sistemas hoteleiros. São Paulo: Senac, 1997.

FARIA, A. M. R.; QUELHAS, O. L. G. A formação profissional e as políticas públicas de educação no Brasil. Boletim Técnico Organização e Estratégia, v. 1, n. 1, p. 16-34, 2005.

GORINI, A. P. F.; MENDES, E. F. Setor de Turismo no Brasil: Segmento de Hotelaria. Brasília: BNDES, set. $2005 . \quad$ Disponível em: <http://www.bndespar.gov.br/SiteBNDES/export/sites/default/bndes_pt/Galerias/Arqui vos/conhecimento/bnset/set2205.pdf>. Acesso em: 19 dez. 2011.

GUEDES, V. L. S.; BORSCHIVER, S. Bibliometria: uma ferramenta estatística para a gestão da informação e do conhecimento, em sistemas de informação, de comunicação e de avaliação científica e tecnológica. 2005. Disponível em: <http://dici.ibict.br/archive/00000508/>. Acesso em: 11/11/2010.

HENRIQUE, D. C; CUNHA, S. K. Metodologias, recursos e práticas didáticopedagógicas no ensino de empreendedorismo em cursos de graduação e pós-graduação nacionais e internacionais. In: ENCONTRO DA ASSOCIAÇÃO NACIONAL DE PÓS-GRADUAÇÃO E PESQUISA EM ADMINISTRAÇÃO, 2006. Bahia. Anais... Salvador: ANPAD, 2006. CD ROM.

KLEMENT, C. F. F; YU, A. S. O. Inovação em serviços: estudo de casos de inovação tecnológica em uma organização hoteleira. In: ENCONTRO DA ASSOCIAÇÃ̃O NACIONAL DE PÓS-GRADUAÇÃO E PESQUISA EM ADMINISTRAÇÃO, 2008a. Rio de Janeiro. Anais... Rio de Janeiro: ANPAD, 2008. CD ROM.

KLEMENT, C. F. F. Serviços em Hotelaria: Estudo de Casos sobre Inovação em Hospitalidade. In: ENCONTRO DA ASSOCIAÇÃO NACIONAL DE PÓSGRADUAÇÃO E PESQUISA EM ADMINISTRAÇÃO, 2010. Rio de Janeiro. Anais... Rio de Janeiro: ANPAD, 2010. CD ROM.

MARQUESAN, F. F. S.; GUZZO, R. F.; SANTOS, S. de A.; ZAWISLAKI, P. A. In: ENCONTRO DA ASSOCIAÇÃO NACIONAL DE PÓS-GRADUAÇÃO E PESQUISA EM ADMINISTRAÇÃO, 2011. Rio de Janeiro. Anais... Rio de Janeiro: ANPAD, 2011. CD ROM.

MELLO. A. S. de; PIMENTEL, M. P. C. O Desenvolvimento de Competências no Setor Hoteleiro Capixaba. In: ENCONTRO DA ASSOCIAÇÃO NACIONAL DE PÓS- 
GRADUAÇÃO E PESQUISA EM ADMINISTRAÇÃO, 2010. Rio de Janeiro. Anais... Rio de Janeiro: ANPAD, 2010. CD ROM.

MIRANDA, A. L. Perspectivas Acadêmicas em São Luis: a aproximação entre o estudo do turismo e a ciência da administração. In: ENCONTRO DA ASSOCIAÇÃO NACIONAL DE PÓS-GRADUAÇÃO E PESQUISA EM ADMINISTRAÇÃO, 2007. Rio de Janeiro. Anais... Rio de Janeiro: ANPAD, 2007. CD ROM.

NICKEL, S.; NICOLITSAS, P.; DRYDEN, N. What makes firms perform well? European Economic Review, v. 41, n. 3-5, p. 783-796, 1997.

PORTER, M. E. Estratégia competitiva: técnicas para análise de indústrias e da concorrência. 7. ed. Rio de Janeiro: Campus, 1992.

REYNOLDS, P. D.; BYGRAVE, W. D.; AUTIO, E.; BOSMA, N. Global Entrepreneurship Monitor: Executive Report. Londres: Babson College, London Business School and Kauffman Center, 2007.

ROCHA, E. L. C; BACCHI, G. A. Ensino de empreendedorismo nos cursos de graduação em administração na cidade de Fortaleza: um estudo comparativo dos conteúdos e instrumentos pedagógicos. In: ENCONTRO DA ASSOCIAÇÃO NACIONAL DE PÓS-GRADUAÇÃO E PESQUISA EM ADMINISTRAÇÃO, 2010. Rio de Janeiro. Anais... Rio de Janeiro: ANPAD, 2010. CD ROM.

RODRIGUES, M. T. O fenômeno do empreendedorismo e as teorias organizacionais: identificando a interseção teórica dos domínios. In: ENCONTRO DA ASSOCIAÇÃO NACIONAL DE PÓS-GRADUAÇÃO E PESQUISA EM ADMINISTRAÇÃO, 2007. Rio de Janeiro. Anais... Rio de Janeiro: ANPAD, 2007. CD ROM.

SAAB, W. G. L.; DAEMON, I. G. Qualidade na hotelaria: o papel de recursos humanos. São Paulo. Senac, 2000.

SCHUMPETER, J. A. Teoria do desenvolvimento econômico. São Paulo: Fundo de Cultura, 1984.

SEIFFERT, P. Q. Empreendendo Novos Negócios em Corporações: Estratégias, processos e Melhores Práticas. São Paulo: Atlas, 2005.

STEL, A.; CARREE, M.; THURIK, R. The effect of entrepreneurial activity on national economic growth. Small Business Economics, v. 24, n. 3, p. 311-321, 2005.

Recebido em: 14-03-2012.

Aprovado em: 14-04-2012. 